\title{
Estratégias políticas na formação docente: diálogo e interações entre sujeitos, instituições formadoras e sociedade*
}

\author{
Lúcia Helena Schuchter \\ Adriana Rocha Bruno
}

\section{Resumo}

Este capítulo é um recorte de uma pesquisa de doutorado, concluida em 2017, que objetivou investigar como se constituíram, historicamente, as políticas públicas de formação docente para o uso das Tecnologias Digitais da Informação e da Comunicação na rede municipal de ensino de Juiz de Fora. A investigação é de cunho qualitativo, na abordagem histórico-cultural, respaldada por Vygotsky e Bakhtin e associada ao "ciclo de políticas” (BALL, 1994). A pesquisa defende que, para a constituição e execução das políticas públicas educacionais, é necessária a configuração de uma arquitetônica cíbrida (SCHUCHTER, 2017). Os "contextos do ciclo das políticas” (BALL, 1994) precisam se reconhecer como instâncias corresponsáveis pela melhoria na educação.

Palavras-chave: arquitetônica cíbrida, formação de professores; política pública; tecnologias digitais.

\section{Political strategies in teacher training: dialogue and interaction between subjects, training institutions and society}

\section{Abstract}

This chapter is a part of a phd research, completed in 2017, aimed to investigate how constituted, historically, public policies of teacher training

* Texto baseado no $8^{\circ}$ capítulo da tese "Escola.edu: as políticas públicas de formação docente para o uso das tecnologias digitais na rede municipal de ensino de Juiz de Fora" (SCHUCHTER, 2017), intitulado: O "contexto da estratégia política”: interesses e atores instituindo a arquitetônica cíbrida. 
for the use of Digital Technologies of Information and Communication in the municipal education of Juiz de For a. The research is qualitative, in the cultural-historical approach, endorsed by Vygotsky and Bakhtin, associated with Ball's "policy cycle" (BALL, 1994). The research argues that, for the constitution and execution of public educational policies, it is necessary to configure a cybrid architecture (SCHUCHTER, 2017). The "policy cycle contexts" (BALL, 1994) need to be recognized as co-responsible instances for improvement in education.

Keywords: cybrid architecture, teacher training; public policy; digital technologies.

\section{Estrategias políticas en la formación docente: diálogo e interacciones entre sujetos, instituciones formadoras y sociedade}

\section{Resumen}

Este capítulo es un recorte de una investigación de doctorado, terminado en 2017, que objetivó investigar cómo se constituyeron, históricamente, las políticas públicas de formación docente para el uso de las Tecnologías Digitales de la Información y de la Comunicación en la red municipal de enseñanza de Juiz de Fora. La investigación es de carácter cualitativo, en el abordaje histórico-cultural, respaldada por Vygotsky y Bakhtin y asociada al "ciclo de políticas" (BALL, 1994). La investigación defiende que, para la constitución y ejecución de las políticas públicas educativas, es necesaria la configuración de una arquitectónica cíbrida (SCHUCHTER, 2017). Los "contextos del ciclo de las políticas" (BALL, 1994) necesitan reconocerse como instancias corresponsables por la mejora en la educación.

Palabras clave: arquitectónica cíbrida, formación de profesores; política pública; tecnologías digitales.

\section{Introdução: uma visão sobre a pesquisa}

Apresentaremos um recorte de uma pesquisa de doutorado (SCHUCHTER, 2017), que partiu da seguinte questão investigativa: como vêm se constituindo, historicamente, as políticas públicas de formação docente com/para o uso das Tecnologias Digitais da Informação e da Comunicação (TDIC) na rede municipal de ensino de Juiz de Fora? A investigação foi de cunho qualitativo, na abordagem histórico-cultural, respaldada por Lev S. Vygotsky e 
Mikhail Bakhtin e nos estudos de Freitas (2003), associada ao "ciclo de políticas" de Ball (BALL, 1994) e aos "métodos de pesquisa na internet", de Fragoso, Recuero e Amaral (2012). O campo de pesquisa se constituiu do Ministério da Educação, da Secretaria de Educação (SE) do Município de Juiz de Fora (JF) e escolas públicas da rede municipal. Os 48 sujeitos foram: (a) dois profissionais do MEC; (b) um chefe do Departamento de Formação da SE-JF, duas supervisoras de formação docente da SE-JF, dois profissionais responsáveis pelo Núcleo de Tecnologia Municipal [NTM] e (c) sete profissionais que foram responsáveis pelo NTM - em gestões administrativas anteriores - e 34 profissionais responsáveis pelos Laboratórios de Informática (LI) das escolas municipais. Os procedimentos metodológicos consistiram em levantamento bibliográfico, análise de documentos, entrevistas semiestruturadas, grupo focal e questionários.

A partir das proposições de autores que deram embasamento à investigação, sinalizamos que os "contextos do ciclo de políticas" (BALL, 1994), nas estruturas macro e micro, foram contemplados: (a) o "da influência", ao apontar o contexto internacional que dita diretrizes e ações que interferem nas políticas públicas educacionais brasileiras; (b) o "da produção do texto", em que os textos políticos são construídos, via entrevistas com profissionais do MEC e por meio dos textos legais oficiais apresentados; (c) o "da prática", na revisão de literatura e no processo de releitura/adaptação das políticas públicas do MEC pela SE-JF e pelas escolas, sendo que nestas, pode-se buscar (d) "os efeitos" - ou não - nos espaços, nas práticas, nos atores envolvidos; na busca por soluções, nas escolhas diante das dificuldades/impasses, isto é (e) na "estratégia política".

A análise de dados foi organizada em duas categorias: (1) Infraestrutura [Recursos humanos, materiais e tecnológicos]; (2) Superestrutura [Uso pedagógico- cultural das TDIC; Ações e estratégias formativas].

Dentre os achados, percebeu-se que as Políticas Públicas de Formação Docente para o Uso das Tecnologias (doravante PPF- 
DUT) oferecidas pelo NTM são releituras do Proinfo 40, minicursos, oficinas e palestras que tentam atender a demanda dos professores que frequentam o Grupo de Estudos de Informática; há escolas sem Laboratórios de Informática, sem internet ou com internet lenta e com problemas na rede elétrica; não há um planejamento do tempo na maioria das escolas para estudos sobre leis e políticas públicas e para formação para o uso das TDIC; o NTM apresenta problemas infraestruturais. Outro fator relevante é que há uma rotatividade muito grande dos chefes de departamento de formação e suas equipes de trabalho, dos responsáveis pelo NTM e dos professores que trabalham nos LI das escolas. Desta forma, não há uma continuidade/aprofundamento nos cursos de formação oferecidos pelo NTM/SE- JF, já que a cada equipe de transição são realizados novos cursos e novos encaminhamentos. Traremos, a seguir, alguns apontamentos sobre tal fato, muito recorrente nos municípios brasileiros.

\section{A política nacional e a local: (des)continuidades e enfrentamentos}

Sarmento (2012) declara que as descontinuidades nas políticas educacionais, provocadas pelas mudanças nas propostas de governo, refletem-se nas políticas locais e aponta que na Constituição de 1988 e na Lei de Diretrizes e Bases da Educação no

9394/96 observa-se a incumbência centralizada na União de conduzir o processo educacional com a definição de prioridades para o alcance da melhoria da qualidade do ensino. Tal processo deve ser conduzido em regime de colaboração - apesar das dificuldades em estabelecê-lo em torno de uma única proposta política com os sistemas locais (estaduais e municipais) de ensino. Todavia, alega que a expectativa de democratização - que tal fato, a princípio, gerou - foi sendo desfeita com ações do governo central voltadas para homogeneizar o processo educacional, tais como avaliações em larga escala, políticas dirigidas aos municípios - como o PDE (Plano de Desenvolvimento da Educação), que estabelece as "Me- 
tas Compromisso Todos pela Educação", ao qual todos os municípios devem aderir - e vinculação de transferência de recursos à adesão a programas de governo. À União cabe a função normativa, redistributiva e supletiva em relação às demais instâncias; enfim, o MEC tem sido formulador e apoiador técnico das políticas e os níveis subnacionais as implementam.

Desta forma, algumas ações passaram a ser desenvolvidas pelas Secretarias de Educação ou mesmo pelas escolas, favorecendo a incorporação da política nacional pela política local.

Lagares (2015) nos alerta, porém, que as relações instituídas entre os sistemas estadual, municipais e as redes de ensino podem ser caracterizadas como mediação de programas do governo federal e não como compartilhamento justo e equitativo de tarefas e custos das políticas educacionais do que deveria ser o regime de colaboração:

Precisamos observar se o que está sendo instituído sobrecarrega os Municípios, se há o debate/diálogo necessário evitando as decisões unilaterais e permitindo a discussão dos possíveis obstáculos econômicos, políticos, legislativos; se há uma política de financiamento; [...] se garante ou compromete a oferta da educação de qualidade, um bem público e direito social de todas as pessoas, em todos os níveis, etapas e modalidades. [...] Isto, considerando [...] um país em que a União, a instância que mais arrecada, não assume a responsabilidade pela educação básica, deixando enormes problemas para Estados e Municípios; um país em que a maioria dos Municípios tem recursos limitados para suprir as necessidades básicas na educação; um país em que a política partidária permeia as relações de poder em seus Municípios. [...] Há um Brasil real que precisa do enfrentamento às disputas de poder, que precisa de definições acerca do regime de colaboração. (n.p.)

Para Estevão e Passos (2015) - ao mencionarem o Proinfo no contexto da descentralização da política educacional brasileira "esta é uma descentralização que se assenta na tradicional divisão de função: um decide (planeja, financia, controla) e outro executa" (p.209). E complementam que conforme dados do Ministério da 
Educação e da Controladoria Geral da União, até 2013, um total de 92\% dos 5.561 municípios brasileiros que já havia aderido ao Proinfo não teve aumento no volume da receita disponível, mas teve aumento nos custos, seja com a remuneração dos professores multiplicadores, dos técnicos do Núcleo, da segurança do laboratório, do mobiliário, das instalações elétricas dos laboratórios. "Então, os custos são maiores do que os benefícios" (p.209), muitos encargos estão sendo transferidos sem os recursos e muitas decisões ficam a critério dos executores. E a questão financeira vai afetar também o quadro de professores em diferentes redes de ensino e a qualidade da formação e dos formadores:

As enormes diferenças de condições financeiras entre governos estaduais e, especialmente, de governos municipais, muitos dos quais dependem sobremaneira de repasses de verbas da União para seus dispêndios públicos, pode levar tanto à descaracterização de uma carreira profissional docente quanto ao descaso dos gestores no que se refere à qualidade de sua base de formação. Muitos desses entes federados também não possuem quadros adequados ao exercício de planejamento e execução de uma gestão pública da educação escolar, justamente por aspectos ligados à formação na área da educação. (GATTI, BARRETTO, ANDRÉ, 2011, p.95)

Complementando esta instância problematizadora, Rodrigues (2015) ensina que "a eficiência das políticas públicas depende do grau de eficiência da gestão" (p.24) que implica a qualidade dos gestores para exercer seu ofício público e um ambiente de atuação "que favoreça a governança democrática e responsabilização política" (Id.). E sugere que para que as ações surtam um efeito positivo, é preciso que os atores políticos sejam capazes de diagnosticar e analisar "a realidade social, econômica e política em que vivem, mas também para interagir e negociar de forma democrática com os diferentes atores envolvidos no processo" (p.25).

Entendemos, neste estudo, que o ciclo de políticas é contínuo e constituído por contextos que apresentam arenas, lugares e grupos de interesse e cada um deles envolve disputas e embates (BOWE; BALL; GOLD, 1992; BALL, 1994), mas aprendemos que 
todas as vozes-signos precisam ser ouvidas (independentes de cargos, partidos políticos, lugares sociais) na construção da política e que o gestor público, segundo Rodrigues (2015), precisa ser comprometido com a "ousadia de propor novas formas de participação democrática” (p.78). Neste viés, Bakhtin [Voloshinov] (1988) postula que a linguagem autoritária reduz o discurso a uma única voz, empobrecendo a comunicação humana, a interação verbal:

O signo se torna a arena onde se desenvolve a luta de classes. [...] É este entrecruzamento dos índices de valor que torna o signo vivo e móvel, capaz de evoluir. O signo, se subtraído às tensões da luta social, se posto à margem da luta de classes, irá infalivelmente debilitar-se, degenerará em alegoria, tornar-se-á objeto de estudos dos filólogos e não será mais um instrumento racional e vivo para a sociedade. A memória da história da humanidade está cheia destes signos ideológicos defuntos, incapazes de constituir uma arena para o confronto dos valores sociais vivos. [...] A classe dominante tende a conferir ao signo ideológico um caráter intangível e acima das diferenças de classe, a fim de abafar ou de ocultar a luta dos índices sociais de valor que aí se trava, a fim de tornar o signo monovalente. (BAKHTIN/VOLOSHINOV, 1988, p. 46-47)

Essa "luta" está presente no "ciclo de políticas", cujos autores, segundo Mainardes (2006), apontam que o foco da análise das políticas públicas:

[...] deveria incidir sobre a formação do discurso da política e sobre a interpretação ativa que os profissionais que atuam no contexto da prática fazem para relacionar os textos da política à prática. Isso envolve identificar processos de resistência, acomodações, subterfúgios e conformismo dentro e entre as arenas da prática, e o delineamento de conflitos e disparidades entre os discursos nessas arenas. (p.50)

A questão central nesta pesquisa é a implementação da política pública para a formação docente para o uso das TDIC no município de Juiz de Fora, buscando a compreensão sobre como as propostas do MEC têm sido incorporadas na rede de ensino. $\mathrm{O}$ olhar aqui se concentra no processo sócio-histórico de construção 
dessa política pública, que se efetiva através de um procedimento decisório constituído por escolhas, intenções, resistências ou aceitação às propostas, definição de prioridades, de ações, que objetivam atender às demandas formacionais. As relações entre o governo federal e os sistemas municipais de ensino configuram específicas formas de construção das políticas, compreendendo diferenciadas arenas de interesses, negociações e interpretações em contextos locais: os arranjos institucionais, as atitudes e objetivos dos atores políticos. Andrade et al. (2015) nos inquietam ao mencionar que a dinâmica de materialização das políticas é permeada por condicionantes que incluem motivações político-ideológicas, grau de interesse dos sujeitos sociais envolvidos, o ritmo e as peculiaridades das instituições corresponsáveis:

Isso significa que determinado programa, projeto ou outra forma de viabilização da ação governamental, concebido para o âmbito municipal e/ ou estadual e/ou nacional, pode apresentar impactos bem diferentes ou até mesmo não se concretizar dependendo dos sentidos e significados construídos nos diferentes contextos em que acontece sua implementação. (p.52)

As políticas públicas de formação docente para uso das TDIC na rede de ensino de Juiz de Fora estão sendo implementadas em contextos desiguais e com diferentes "resultados/efeitos" (mudanças na instituição e interface com outras políticas setoriais): escolas com e sem laboratórios; com e sem internet; laboratórios bem equipados/adequados e outros mal equipados/inadequados; escolas com professores de LI em todos os turnos e escolas com um único profissional para atender três turnos; professores que participam e que não participam das reuniões e das ações formativas. "Atores e instituições interagem nos processos das políticas públicas” (CONDÉ, 2013, p.83), logo, precisam buscar táticas para vencer tantos desafios. Neste viés, em relação ao contexto "da estratégia política”, Mainardes (2006, p.68-69) lança algumas perguntas para ajudar a condução da pesquisa, tais como: que estratégias 
poderiam ser delineadas para lidar com as desigualdades, os impasses? Que aspectos podem ser repensados e redimensionados? Como tais estratégias podem ser disseminadas? Mas entre desigualdades e problemas, há enfrentamentos e possibilidades verbalizados no "contexto da prática", que vão sendo sinalizados, rumo às "estratégias políticas". Bakhtin (2003) esclarece que

A única forma adequada de expressão verbal da autêntica vida do homem é o diálogo inconcluso. A vida é dialógica por natureza. Viver significa participar do diálogo: interrogar, ouvir, responder, concordar etc. Nesse diálogo o homem participa inteiro e com toda a vida: com os olhos, os lábios, as mãos, a alma, o espírito, todo o corpo, os atos. Aplica-se totalmente na palavra, e essa palavra entra no tecido dialógico da vida humana, no simpósio universal. (p.348)

\section{A "estratégia política" dos atores educacio- nais: rumo à arquitetônica cíbrida}

Que indicações, proposições, sugestões advêm do diálogo com os sujeitos? O que tem funcionado - ou não - nas PPFDUT na rede municipal de Juiz de Fora? Entre interrogações, respostas, concordâncias ou discordâncias, surge a voz manifesta pelos sujeitos da pesquisa. O que têm a dizer, a propor, a indicar? Eis que trazemos as suas palavras para apresentar algumas proposições ("estratégias políticas") para as práticas formativas que ocorrem na rede municipal de ensino de Juiz de Fora. Ball (2006) também nos ensina que:

As políticas normalmente não nos dizem o que fazer, elas criam circunstâncias nas quais o espectro de opções disponíveis sobre o que fazer é reduzido ou modificado ou nas quais metas particulares ou efeitos são estabelecidos. Uma resposta ainda precisa ser construída no contexto, contraposta ou balanceada por outras expectativas. Tudo isso envolve algum tipo de ação social criativa. (p. 26).

Segundo Mainardes (2006), o aspecto essencial do contexto "da estratégia política" é o compromisso do pesquisador em contribuir para "o debate em torno da política, bem como para sua com- 
preensão crítica” (p.60). Logo, este percurso investigativo não pôde prescindir de um exercício de "escutar" o profissional na busca por respostas às suas necessidades contextuais.

Assim, realçamos, ainda em tempo e dentro desta instância problematizadora, algumas falas dos sujeitos ${ }^{2}$ que expõem aspectos acerca da formação e de situações vivenciadas na rede de ensino municipal, argumentando e indicando caminhos ("contexto da estratégia política", BALL, 1994), tais como a inclusão da Universidade e da escola na formação, justificativa para o horário extraclasse, concurso para professores, dentre outros. Eis algumas proposições dos professores dos LI das escolas (E-LI):

Acredito que as reuniões podem ser mais produtivas se acontecerem alternadamente em um laboratório de informática e em outros espaços de interação. A universidade seria um deles.

Também é importante que as reuniões sejam obrigatórias e aconteçam dentro do horário de trabalho, pois o extraclasse é exclusivo para planejamento. A formação em contexto deve ser priorizada pela Secretaria de Educação, dando oportunidade a todos de participarem.

Oferecer mais cursos a distância.

S3 e E6 também têm algo a nos dizer:

S3: Eu penso que deveria ser uma equipe maior. [...] Eu considero que poderíamos fazer um trabalho muito mais significativo se tivéssemos a incumbência com a formação somente na área da tecnologia.

2 Foram resguardados no anonimato os nomes de todos os profissionais envolvidos na pesquisa. Tal opção se deve ao fato do compromisso de sigilo com eles firmado pelas pesquisadoras. Foram usadas letras: $\mathbf{M}$ para os profissionais do MEC; $\mathbf{S}$ para os da Secretaria de Educação de JF; E para os das escolas, sendo: (a) E1 a E7 os professores que já foram responsáveis pelo NTM (em gestões administrativas anteriores) e (b) E-LI, os professores dos LI (Escolas - Laboratórios de Informática) das escolas da rede municipal. 
E6: Os cursos da área de tecnologias [...] deveriam ser descentralizados, ou seja, na própria escola, utilizando as reuniões pedagógicas ou horárias extraclasses.

Neste ponto específico da chamada formação em serviço ou Horário de Trabalho Pedagógico Coletivo ou horário extraclasse ${ }^{3}$, temos leis e orientações que amparam e oferecem este direito ao professor, mas a Lei $\mathrm{n}^{\circ} 9732^{4}$, que regulamenta a jornada semanal do pessoal do quadro do magistério municipal de Juiz de Fora, em seu Artigo 20, expressa: “as horas restantes da jornada ficam destinadas ao exercício de atividades docentes extraclasses, não sendo estas atividades, obrigatoriamente, exercidas na escola”. Esta premissa dificulta a articulação de ações e práticas de planejamento e formação na escola, já que o professor não precisa, obrigatoriamente, nela permanecer - o que, geralmente, é a sua opção - prejudicando uma possibilidade de pensar o planejamento e a formação coletiva com seus pares. Neste enfrentamento, a equipe gestora é fundamental para articular e justificar momentos de formação, des-

3 Há a garantia da formação em serviço em várias leis e estudos: Previsto no artigo 67, V, da Lei de Diretrizes e Bases da Educação (BRASIL, 1996, n.p.) BRASIL, Lei no 11.738, de 16 de julho de 2008. Piso salarial profissional nacional para os profissionais do magistério público da educação básica. Disponível em: http://www.planalto.gov.br/ccivil_03/_ato2007-2010/2008/ lei/111738.htm Acesso: outubro de 2016. BRASIL. Documento Final da CONAE. 2010. Disponível em: http://pne.mec.gov.br/images/pdf/CONAE2010_doc_final.pdf. Acesso: outubro de 2016.

BRASIL. Estudo sobre a lei do piso salarial. 25 de setembro de 2012. Disponível em: http://portal.mec.gov.br/index.php?option=com_docman\&view=download\&alias $=10241$-estudo-sobre- $\quad$ lei-piso-salarial $\&$ Itemid $=30192$. Acesso: outubro de 2016.

BRASIL. Documento Final da CONAE. 2014. Disponível em: http://fne.mec.gov.br/images/doc/DocumentoFina240415.pdf. Acesso: outubro de 2016.

4 JUIZ DE FORA, Lei no 9732, que regulamenta a jornada semanal do pessoal do quadro do magistério municipal de Juiz de Fora, adequando à disposição federal. Disponível em: https:/ / c-mara-municipal-da- juiz-de-fora. jusbrasil.com.br/legislacao/328273/lei-9732-00 Acesso: janeiro de 2017. 
de que significativos e concebidos em diálogo com toda a comunidade escolar. Afinal,

Jogar o jogo da política democrática, ética e da justiça social é o desafio que os gestores de políticas públicas têm de enfrentar para planejar, administrar e extrair recursos e formatar políticas redistributivas que busquem promover sociedades mais iguais e mais livres. (RODRIGUES, 2015, p. 78)

Para Sarmento (2010), "é preciso respeitar o corpo docente, garantir formação permanente e condições de trabalho adequadas. Nenhuma política se concretizará se não contar com a adesão dos professores" (p.41). Defendemos, pois, que precisam conhecê- las, porém:

Políticas serão interpretadas diferentemente uma vez que histórias, experiências, valores, propósitos e interesses são diversos. Os autores dos textos políticos não podem controlar os significados de seus textos. Partes podem ser rejeitadas, selecionadas, ignoradas, deliberadamente mal entendidas, superficialmente respondidas ou não. (BOWE; BALL; GOLD, 1992, p.22)

lógica, em coautoria: com os formadores das universidades, das Secretarias de Educação, com os gestores, com os professores (e não somente para eles). As PPFDUT deveriam estar articuladas às necessidades dos docentes e discentes. A perspectiva dinâmica inerente às TDIC deveria estar nas políticas a elas direcionadas.

A nossa visão é de que há uma intenção, por parte do Governo Federal, de descentralização na execução das políticas públicas, mas não na idealização, que deveria se pautar na participação, na resolução e atendimento às demandas formacionais. Percebe-se que a perspectiva não-dialogal da formulação das políticas na estrutura "macro" (contexto "de influência" e "de produção de texto") se reproduz na estrutura "micro" (contexto "da prática”, BALL, 1994). Desta forma, há mudanças, mas os processos do "fazer política" continuam arcaicos. Seria relevante que esses mesmos órgãos estivessem integrados e articulados em suas funções, atitudes e deci- 
sões coletivas e democráticas. Defendemos que a formação de um professor pesquisador é contínua, permanente, coletiva e em interação com seus pares, obedecendo a uma dinâmica organizacional que dialoga (no sentido bakhtiniano: sem esconder os conflitos e as diferenças) com outras instituições e entidades: MEC, Universidades, Programas de Pós-Graduação, Grupos de Pesquisas, Secretarias de Educação, Escolas, Sindicatos,

Colegiados Escolares, Conselhos Municipais de Educação ${ }^{5}$, Conferência Nacional de Educação ${ }^{6}$ (CONAE), União Nacional dos Dirigentes Municipais de Educação (Undime) etc. Tal dinâmica deveria se pautar em um processo reflexivo e formativo em parceria, "em que atores institucionais corresponsáveis se retroalimentam no diálogo preciso, desejável e promissor" (SCHUCHTER, 2017, p.180). Todas estas ações e posturas devem visar a mudanças de paradigmas na escola, inserida na cultura digital.

Assim, para a constituição e execução das políticas públicas educacionais, seria potente uma configuração que denominamos arquitetônica cíbrida ${ }^{7}$ (SCHUCHTER, 2017). Cíbrido, que no campo da semântica, é aquilo que se espalha, se propaga infiltra, irradia; e, no campo da teoria da comunicação, é ser/estar online e off-line. Logo, a arquitetônica cíbrida é a criação de um todo inte-

5 Um Conselho Municipal de Educação deve ser composto por representantes do governo, da comunidade escolar e da sociedade civil (http://www.todospelaeducacao.org.br/reportagens-tpe/26749/perguntas-e- respostas-o-quesao-e-como-funcionam-os-conselhos-municipais-de-educacao/). Acesso: fevereiro de 2017

6 Organizada para debater sobre a Educação, é realizada, em diferentes espaços institucionais, nos municípios e estados. Dela participam estudantes, Pais, Profissionais da Educação, Gestores, Agentes Públicos e sociedade civil. (http://portal.mec.gov.br/conae-conferencia-nacional-de-educacao-184997880/12422conae-apresentacao). Acesso: fevereiro de 2017.

7 "Para Peter Anders (apud KINSLEY, 2003), cíbrido é a fusão da atualidade e da virtualidade, a conexão entre a realidade que contém os objetos concretos e a virtualidade, que contém os objetos simulados. Os objetos concretos são os objetos reais, atualidade do espaço físico que habitamos, entendido como constituídas por unidades básicas de existência (átomos). Já o virtual 
grado, onde o real e o virtual se fundem, "em que se estabelecem interações e implicações recíprocas/dialéticas entre sujeitos sociais, instituições formadoras e sociedade" (SCHUCHTER, 2017, p.180). Enfim, apresentamos a imagem, que tenta traduzir e sintetizar a possibilidade da arquitetônica cíbrida:

Figura 1: Arquitetônica cíbrida das PPFDUT - implicações e (inter) ações entre sujeitos, instituições e sociedade
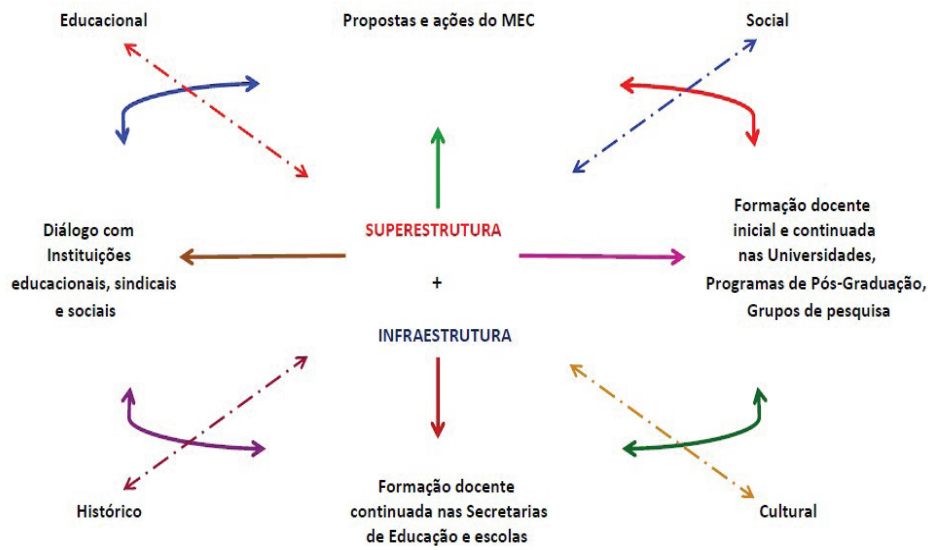

Fonte: elaboração própria (SCHUCHTER, 2017)

Sintetizando, as PPFDUT deveriam ser integradas e compartilhadas entre todos os órgãos. É na articulação e alinhamento com outras políticas, nos debates travados nas várias entidades educacionais, sindicais e sociais, que será determinada sua real execução

é relacionado ao espaço computacional e suas unidades que o compõem, os bits". (HAMDAN, 2009, n.p.). "Somos ON e OFF ao mesmo tempo, simbioticamente, formando um ser maior que o nosso corpo/cérebro biológico nos expandindo para todo tipo de dispositivo e abrangendo outras mentes e corpos. Somos cíbridos. (...) Não precisamos mais sair de onde estamos para acessar uma máquina que nos leve para o ON. Hoje, e cada vez mais, o ON está com a gente onde quer que estejamos e, em breve, estará conectado direto no nosso cérebro.” (GABRIEL, 2012, n.p.) 
e adoção. Há que se ter apoio (sistêmico, interdependente, cooperativo) dos órgãos públicos - MEC, Universidades, SE e escolas - e serem conduzidas por um viés dialógico em que todos assumam o papel de atores (aqueles que agem) políticos. constituídas por unidades básicas de existência (átomos). Já o virtual é relacionado ao espaço computacional e suas unidades que o compõem, os bits". (HAMDAN, 2009, n.p.).

"Somos ON e OFF ao mesmo tempo, simbioticamente, formando um ser maior que o nosso corpo/cérebro biológico nos expandindo para todo tipo de dispositivo e abrangendo outras mentes e corpos. Somos cíbridos. (...) Não precisamos mais sair de onde estamos para acessar uma máquina que nos leve para o ON. Hoje, e cada vez mais, o ON está com a gente onde quer que estejamos e, em breve, estará conectado direto no nosso cérebro." (GABRIEL, 2012 , n.p.) trazem em seu bojo, ao mesmo tempo, um direito e uma possibilidade de resposta: o ato responsável-responsivo ${ }^{8}$ (de o professor "formar-se", de o gestor possibilitar a formação, de o poder público condicionar e dar suporte técnico e financeiro etc.), pois para Bakhtin, viver é "tomar posições continuamente, enquadrar-se em um sistema de valores e, do interior dele, responder axiologicamente" (COVRE, NAGAI, MIOTELLO, 2009, p. 64).

O saber - com legitimidade, como direito, como ato intencional, como responsabilidade - é empoderador e pode ser erigido com alegria e esperança, disponibilidade ao diálogo, comprometimento e criticidade, como nos ensina Freire (1996).

Souza (2006) nos alerta: política pública é campo do conhecimento que busca colocar o governo em ação e/ou analisar essa ação e, quando necessário, propor mudanças no rumo ou curso dessas ações. Bonilla (2011) assinala que professores e alunos pre-

8 "O ato responsável é o ato baseado no reconhecimento da obrigatória singularidade. [...] É o fato vivo de um ato primordial ao ato responsável [...]; ele é o fundamento da vida como ato, porque ser realmente na vida significa agir, é ser não indiferente ao todo na sua singularidade." (BAKHTIN, 2010, p.99, grifo nosso) 
cisam ter voz e vez nesse contexto, participar do processo como autores, colaboradores. Diz, ainda, que professores podem se constituir sujeitos fortes, dispondo de suporte tecnológico:

Evidentemente, para isso, é necessária política pública que democratize $\mathrm{o}$ acesso às tecnologias e fortaleça os processos de formação de professores, formação inicial, permanente e continuada [...]. É necessário também repensar os currículos dos cursos de formação de professores para incorporar todas as dinâmicas da Web 2.0. [...] Temos todos, professores formadores, universidades e governos muito a estudar, elaborar e propor - longo caminho a ser trilhado! (p.83)

Longo caminho em que todos os "contextos do ciclo das políticas” (BALL, 1994) precisam se reconhecer como instâncias corresponsáveis pela melhoria na educação, sendo os docentes [e suas ações pedagógicas e formativas] elementos fundamentais para se repensar as políticas de formação, pois nas instituições escolares se concretizam [ou não] os efeitos, as resistências, as releituras/ adaptações e os novos rumos dessas políticas - num processo de empoderamento dos sujeitos em suas decisões, escolhas e percursos de vida pessoal e profissional.

\section{Referências}

ANDRADE, E. F. A. et al. Programa Nacional de Tecnologia Educacional (PROINFO): uma análise de experiências vivenciadas em Pernambuco. Revista de Administração Educacional, Recife, v.1, n 1, p.51-67, jan./jun 2015. Disponível em: http://revista.administracaoeducacional.com.br/artigos/04_20151.pdf Acesso: agosto de 2018.

BAKHTIN, M. [VOLOSHINOV]. Marxismo e filosofia da linguagem. $4^{a}$ ed. São Paulo: Hucitec, 1988. Estética da criação verbal. SP: Martins Fontes, 2003.

Para uma filosofia do Ato Responsável. Trad. V. Miotello e C. A. Faraco. São Carlos: Pedro \& João Editores, 2010.

BALL, S. J. Educational reform: a critical and post-structural approach. Buckingham: Open University Press, 1994. 
Sociologia das políticas educacionais e pesquisas crítico-social: uma revisão pessoal das políticas educacionais e da pesquisa política educacional. Currículo sem fronteiras, v. 6, $\mathrm{n}^{\circ}$ 2, p.10-32, jul./dez. 2006.

BONILLA, M. H. S. Formação de professores em tempos de web 2.0. In: FREITAS, M. T. A. (org.). Escola, tecnologias digitais e cinema. Juiz de Fora: Ed. UFJF, 2011.

BOWE, R.; BALL, S.; GOLD, A. Reforming education and changing schools: case studies in Policy Sociology. London: Routledge, 1992.

CONDÉ, E. S. Abrindo a caixa: dimensões e desafios na análise das políticas públicas. Pesquisa e debate em Educação, v.2, p. 78-100, 2013.

COVRE, A. M.; NAGAI, E. e MIOTELLO, V. (orgs.) Palavras e contrapalavras: glossariando conceitos, categorias e noções de Bakhtin. São Carlos: Pedro e João Ed., 2009.

ESTEVÃO, R. B; PASSOS, G. O. O Programa Nacional de Tecnologia Educacional (PROINFO) no contexto da descentralização da política educacional brasileira. HOLOS, Ano 31, v. 1, p.199 - 213, 2015. Disponível em: http://www2.ifrn.edu.br/ ojs/index.php/HOLOS/article/view/2645/pdf_159 Acesso: setembro de 2016.

FRAGOSO, S.; RECUERO, R.; AMARAL, A. Métodos de pesquisa para internet. Porto Alegre: Sulina, 2012.

FREIRE, P. Pedagogia da autonomia: saberes necessários à prática educativa. SP: Paz e Terra, 1996.

GABRIEL, M. C. C. Cibridismo: ON e OFF line ao mesmo tempo. Martha Gabriel Blog. 02 de maio de 2012. Disponível em: https:/ / www.martha.com.br/cibridismo-on-e- off-line-ao-mesmo-tempo/ Acesso: setembro de 2018.

GATTI, B. A.; BARRETTO, E. S. S.; ANDRÉ, M. E. D. Políticas docentes no Brasil: um estado da arte. Brasília: UNESCO, 300 p., 2011.

HAMDAN, C. Ecologia Cíbrida: arte, tecnologia e sistemas vivos. Seminário Cultura Visual, 2009. Disponível em: https://seminarioculturavisual.fav.ufg.br/ up/778/o/2009.GT2_Camila_Hamdan_UnB_P oeticas_V.pdf Acesso em: agosto de 2018.

LAGARES, R. Relações intergovernamentais estado-municípios no Tocantins na educação: regime de colaboração ou arranjos administrativo-legais. 
Anais da 37 ${ }^{a}$ Reunião Nacional da ANPEd. Florianópolis, 2015. Disponível em: http://37reuniao.anped.org.br/wp-content/uploads/2015/02/TrabalhoGT05-4402.pdf. Acesso: setembro de 2016.

MAINARDES, J. Abordagem do ciclo de políticas: uma contribuição para a análise de políticas educacionais. Educação e Sociedade. v. 27, nº 94, p.47-69, jan/ abr 2006.

RODRIGUES, M. M. A. Políticas públicas. SP: Publifolha, 2015.

SARMENTO, D. C. Apresentação. In:. (org.). Sistemas de Educação no Brasil: políticas, autonomia e cooperação. Juiz de Fora: Ed. UFJF, 2010. (org.) Educação e qualidade: sistemas educacionais em construção. JF: Ed. UFJF, 2012.

SCHUCHTER, L. H. Escola.edu: as políticas públicas de formação docente para o uso das tecnologias digitais na rede municipal de ensino de Juiz de Fora. Tese (Doutorado em Educação). UFJF, Juiz de Fora, 2017.

SOUZA, C. Políticas Públicas: uma revisão da literatura. Sociologias. Porto Alegre, ano 8, n 16, p. 20-45, jul/dez. 2006.

\section{LÚCIA HELENA SCHUCHTER}

CV Lattes: http://lattes.cnpq.br/9689630982789965 ORCID: https://orcid.org/0000-0003-1424-309X

e-mail: luciahschuchter@yahoo.com.br telefone: (32) 98824-9987

Endereço residencial: Rua José Lourenço, 265 - São Pedro- Juiz de Fora - MG, CEP: 36036-230

\section{ADRIANA ROCHA BRUNO}

CV Lattes: http://lattes.cnpq.br/9966072704077985 ORCID: https://orcid. org/0000-0002-5646-8919

e-mail: adriana.bruno@educacao.ufff.br telefone: (32) 9 9912-7829

Endereço residencial: Rua Profa Aracy Nazareth, 440 - Spina Ville II - Juiz de Fora - MG - CEP: 36037-782 